\title{
The Big Bad Wolf: The Formation of a Stereotype
}

\author{
Uta Maria Jürgens ${ }^{1,2}$ and Paul M.W. Hackett ${ }^{3,4,5}$ \\ ${ }^{1}$ Department of Environmental Systems Science, Swiss Federal \\ Institute of Technology Zürich ETHZ, Zürich, Switzerland. \\ ${ }^{2}$ Social Sciences in Landscape Research Group, Swiss Federal \\ Research Institute WSL, Birmensdorf, Switzerland. \\ ${ }^{3}$ Department of Psychology, University of Gloucestershire, \\ Cheltenham, UK. \\ ${ }^{4}$ Department of Psychology, University of Cambridge, Cambridge, UK. \\ ${ }^{5}$ Emerson College, School of Communication, Boston, \\ Massachusetts, USA.
}

\section{Abstract}

In this paper we consider the negative sentiments surrounding the return of the wolf to Central Europe. Management plans devised to facilitate human-wolf coexistence have largely focused on wolf biology and the economic implications of the wolf's presence in attempts to inform people and address practical concerns. Yet many people's attitudes toward wolves do not seem in accord with biologically based knowledge. In this essay, we argue that there are deeply rooted implicit beliefs and feelings that mitigate against a rationally based understanding of, and coexistence between, humans and wolves in Central Europe. Specifically, we propose that negative feelings toward wolves are in part associated with aspects of actual wolf behavior, which correspond to the human understanding of the notion of evil. This correspondence appears to give rise to the stereotype of a Big Bad Wolf that may help fuel the heated societal debates about wolves. To conclude, we propose that in order to better understand human-wolf relationships,

(C) Jürgens and Hackett 2017; Published by Mary Ann Liebert, Inc. This Open Access article is distributed under the terms of the Creative Commons Attribution Noncommercial License (http://creativecommons.org/licenses/by-nc/ 4.0/) which permits any noncommercial use, distribution, and reproduction in any medium, provided the original author(s) and the source are credited. information about cultural stereotypes needs to be taken into account. Furthermore, we suggest that consideration of these stereotypes may help inform the debate around human-wolf coexistence. Key Words: Human-wildlife relations-Wolves-StereotypesEvil-Conservation psychology-Human dimensions.

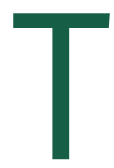

his essay is about the stereotype ${ }^{1}$ of the Big Bad Wolf and how this cliché image may be detrimental to the coexistence of human beings and wolves in contemporary Central Europe. We commence our exploration with an anecdotal account that reflects the pertinence of our explorations into human-wolf relationships.

On a hot summer afternoon, the first author along with her big black shaggy dog "Dagur" descended from a hike in nearby mountains. Turning around a corner, they met an elderly lady who stood clinging onto her hiking sticks, breathing heavily, and appeared dazed from her strenuous ascent. She heard them approaching, opened her eyes, and when she had gathered herself she noticed Dagur and uttered in bewilderment: "He looks like the wolf!" Watching Dagur strolling around the forest, or inspecting an image of Dagur captured in a wildlife biologist's photo trap, there seems little possibility that the dog would be mistaken for a wolf. It seems likely that, had the lady been in a more settled state of mind, she would have recognized and addressed Dagur as a dog. It is of anecdotal interest that the woman did not say that Dagur looks like " $a$ " wolf, but rather he seemed to evoke a baleful and cliché image of "the wolf."

We offer this event to illustrate the possibility that such a mental image exists in the thoughts and cultural memories of people living in Central Europe. It is this image that we equate with the Big Bad Wolf stereotype.

${ }^{1}$ In this essay, we refer to "idea" as an abstract concept whose meaning is deeply ingrained and essentially shared among members of a culture. We take it to be roughly synonymous with the pertinent Jungian term "archetype." In order to denote the psychologically real implementation of an idea/ archetype that actively guides humans' thinking and feeling, we use the term "stereotype." 


\section{JÜRGENS AND HACKETT}

In our essay, we explore this image of a stereotypical Big Bad Wolf, and we explain how many of the themes, which keep resurfacing in debates about wolves in present-day culture, can be thought of as being associated with this stereotype. In order to investigate these possible associations, we consider human perceptions of wolf behavior and evaluate how these may correspond to attributes associated with immorality or wickedness especially as such human characteristics are expressed in the Jungian shadow archetype of evil. We further explore how the stereotype of the Big Bad Wolf may be created through the unconscious merger of actual wolf behavior with notions associated with evil in human beings.

We first delineate the agenda of this essay and then provide a short overview of research on human-wolf relations in Central Europe. We then review aspects of wolf biology that may be particularly salient and potentially problematic to a peaceful coexistence between wolves and humans. Finally, we identify correspondences between those aspects of wolf behavior and the human understanding of what constitutes an evil act and how this correspondence may reinforce the concept of the Big Bad Wolf.

\section{The Purpose and Scope of this Essay}

Following a review of the literature and media, it appeared to the authors that the scientific research on human-wolf relations seems to focus on wolf biology or human sociodemographic variables associated with pro- or antiwolf attitudes. Conversely, there appeared a paucity of research that focused upon "subjective understanding" of people in response to the growing presence of wolves in Central Europe. No research was discovered that, for instance, considers how beliefs and attitudes toward wolves may be rooted in archetypal beliefs. In this paper, we consider how human-wolf relations are both important areas of study in their own right and as a pertinent sample case of how human beliefs and sentiments may impact on humanwildlife relations more generally. Our focus is to expatiate upon how the abstract archetypal idea of evil may impact upon relations of humans to wolves.

It is a truism that attitudes and beliefs vary considerably between times, cultures, and individuals. However, we present what we conceive of as relatively stable patterns of beliefs and sentiments toward wolves in Central Europe. The stability of these outlooks is evidenced, we believe, by their long tradition and recurrence of common themes in cultural depictions of these animals (e.g., covering a time range that is greater than Aesop's fables to Baum's wizard of Oz), which we here merely adumbrate instead of thoroughly documenting them. In accordance with the predominantly negative view of wolves in the Central European tradition (Meurer \& Richarz, 2005), we focus on the pejorative stereotype of the Big Bad Wolf, though in the next section we will shortly comment upon the idolizing stereotype of "wolf the noble savage."

We justify this limitation by emphasizing that our essay seeks to inspire multidisciplinary investigations into the subjective understanding and relationships between humans and wolves by using the negative Big Bad Wolf stereotype as an example. By this example, we seek to highlight the need for ecopsychological research that investigates in depth the effects of the different stereotypes that human beings attach to wolves and to other wildlife.

In order to exemplify the recurring themes in the contemporary debates about wolves, we draw upon illustrative media pieces from print and online journalism, and Web site and blog entries, limiting our choice of sources to German-speaking countries. It is beyond the purpose and scope of this essay to perform a meticulous analysis of media items (for a comprehensive media analysis in Germanspeaking Europe, see, e.g., Kaczensky, 2006). Similarly, we are cognizant of the rich philosophical and theological literature on the concept of evil, and we do not claim to provide a comprehensive account of the cultural understanding of that concept.

Turning to the agenda of this essay, our aim is to undertake a transdisciplinary survey of how the depth psychological phenomenon of "the shadow" (Jung, 1990) may be influential and apparent in human-wolf relations. In our analyses we equate the Jungian terminology of the shadow with the philosophical notion of the idea of evil. We bring together and synthesize references of various sources to interrogate the hypothesis that human reactions to wolves as being evil may be caused by a correspondence between features of wolves' behavior and facets of the shadow archetype. This correspondence would thus give rise to the cultural stereotype of the Big Bad Wolf. We examine ways in which the Big Bad Wolf stereotype may taint contemporary renderings of wolves in societal debates, thus being fueled by and, in turn, reinforcing the implicit association of wolves with possessing the human characteristic of being evil.

Many interpretations of the Big Bad Wolf figure have been offered. They range from Valerius Geist's claim (2007) that the Big Bad Wolf epitomizes a real danger emanating from wolves, to Alison Davies' (2015) proposal that the baleful wolf figure is a mere symbol, illustrating a variety of amorphic human fears. We propose that the various interpretations share a reference to the shadow archetype and that this archetype is also referenced in many contemporary cultural renderings of wolves in the media we explored. Therefore, the pivotal question motivating our inquiry is this: Why is it that in ancient myths and contemporary media, wolves have an unparalleled association with the idea of evil? In European history, people have 


\section{THE BIG BAD WOLF STEREOTYPE}

undoubtedly faced manifest physical and economic threats brought about due to bears or large deer. Likewise, amorphic fears could, theoretically, also be incarnated by other animals than wolves, such as badgers or lynx. Why have wolves-not exclusively, but to an incomparable degree-been depicted as evil?

Numerous further questions may be asked when investigating the intricacy of the relationship between attitudes, stereotypes, and behaviors toward wildlife, especially when this is couched within a cultural and social context. In this essay, we propose answers to some of these questions and pinpoint further ones that require exploration in order to provide meaningful understanding of the "human dimensions" that play a part in human relations with wolves.

\section{Wolf Biology and Behavior}

The region of Central Europe, which we define as embracing Benelux, Germany, Switzerland, Austria, France, and Northern Italy, has been a wolf-free zone for centuries. Its landscape is densely inhabited and intensively used by humans. However, since the 1990s, Eastern European wolves have been returning to live in Eastern Germany, where several packs reside and reproduce. Simultaneously, wolves from residual Italian populations have migrated to France and Switzerland, where multiple individuals are now resident, and wolves from different populations have spread as far as to Northern Germany and the Netherlands. Most individual wolves that have started their migration were used to forested habitats but have adapted to and settled in a wide variety of areas. These include the barren former brown coal-mining landscapes in Brandenburg, Germany, seasonally browsed alpine regions in Switzerland, and intensively farmed areas in Northern Germany and France. From this it is apparent that the animals that were thought of as creatures of the wilderness have adapted to cope well with the cultural (human occupancy dominated) landscape (Ansorge et al., 2010).

In the midst of this fascinating natural phenomenon, wildlife biologists work toward providing objectively informed facts about wolves and about their interactions with humans and thus attempt to mitigate potential stakeholder- and human-wolf conflicts. However, the societal debates about wolves appear fueled by claims and beliefs that exist beyond empirical evidence: People's reactions to their new neighbors range from an exuberant affirmation of wolves' return to outright repudiation. An example of enthusiasm toward wolves is provided by the Swiss registered association CHWOLF, which according to its mission statement seeks to "provide information and knowledge in order to further acceptance of wolves and their reintegration into our environment," thus "reminding everyone of their responsibility to contribute to a better world each day" (first author's translation from chwolf.org). On their Web site, CHWOLF praises wolves for their top-down predatory effects on establishing an ecological equilibrium, and they reiterate a romantic image of a nobly savage wolf by citing Del Goetz' "Wolf Credo," which reads: "Respect the elders, teach the young, cooperate with the pack, play when you can, hunt when you must, rest in between, share your affections, voice your feelings, leave your mark." Accordingly, in their study of people's attitudes toward wolves, Caluori and Hunziker (2001) find that wolf enthusiasts on the one hand cherish the animal for bringing a flair of wilderness to the land and on the other hand create an ethical ideal in the image of wolves.

Conversely, wolf skeptics repudiate wolves for reasons as varied as the resentment expressed by some hunters that wolves compete with them for game (Bisi et al., 2010; Gärtner \& Hauptmann, 2005; Kellert, 1985; Kowitz, 2012; Wotschikowsky, 2006) to farmers' fears for economic loss (e.g., Culiuc, 2015; Deter, 2016b; Ulbrich, 2016) and to mothers' fears for their children's well-being (cf. Deter, 2016a; Schäfli, 2014b; Winter, 2008). Like wolf enthusiasts, wolf skeptics also seem to soak their claims with emotionally tainted prose. For example, Alfons Deter, a journalist writing for the agrarian news blog "topagrar online," says in a commentary: "In many regions we need to face a decision of sacrificing livestock farming to wolf packs who definitely don't have any ecological value whatsoever and who specialize on livestock depredation" (first author's translation of Deter, 2016b).

From the above statements, it seems that both wolf enthusiasts and wolf skeptics are motivated, or at least influenced, by the emotions that are associated with and in turn may distort biological facts about wolves. Therefore, the societal debates about the ecological effects of resurging wolf populations, whether wolves are dangerous, the effects they will have on game densities, or about how to deal with livestock predation are highly contentious. These debates do not primarily address wolf biology as for both pro- and antiwolf lobbies; what is at issue is the implicit beliefs and emotions each group holds (cf. Hasselmann, 2016). Consequently, in order to understand and mediate between people's views about wolves, it is not only wolf biology that must be understood but also how people subjectively perceive and understand wolves and their behavior. Therefore, in order to understand and effectively manage human-wolf relationships and mitigate stakeholder conflicts, conservation professionals must not only look at the roles wolves play in Central European ecosystems, they must also look at the role they play in Central Europeans' minds.

Much of human thinking and feeling, in general, is guided by implicit beliefs, which may be strongly associated with stereotypes 


\section{JÜRGENS AND HACKETT}

(Gawronski \& Payne, 2011). The notion that modern humans may have overcome category-based thinking is refuted in the psychological literature (Macrae \&t Bodenhausen, 2000; Meier et al., 2004). Therefore, when attempting to understand human relationships with wildlife more broadly and with wolves in particular, we must identify the stereotypes that inform people's attitudes (their cognitions, affections, and intentions) toward the wolf. A legion of studies has reported investigations into the sociodemographic variables associated with specific pro- or antiwolf attitudes (for a diverse collection of such studies across countries and decades, see Andersen et al., 2003; Bath \& Majić, 2001; Hunziker et al., 1998; Kaltenborn et al., 1998; Kaltenborn \& Bjerke, 2002; Majić \& Bath, 2010; Skogen, 2001; Skogen \& Thrane, 2007; Wild-Eck \& Zimmermann, 2001; Williams et al., 2002).

In contrast, few researchers have broadened the study of "human dimension" in wildlife research so far as to include the investigation of potentially deeper-seated dispositions (pioneering scholars include Bjerke \&t Kaltenborn, 1999; Caluori and Hunziker, 2001; Egger, 2001; Flykt et al., 2013; Jacobs et al., 2014; Linnell et al., 2015). In particular, there are virtually no empirical studies that have investigated stereotypes, abstract ideas, or attitudes that may be reflected in people's dispositions and behaviors toward wolves. Indeed, from the authors' investigations it appears that possible associations of wolves with human archetypes may be more likely to be implicitly inherent in media coverage than explicitly covered in academic publications.

By choosing topics for discussion and by framing these in a particular manner, the media literally "mediate" information in two ways. For example, journalists may acknowledge their audience's dispositions and then choose themes that are likely to correspond to these. Vice versa, journalists may frame these themes in a way to make the information correspond with people's cognitive and emotional dispositions (McGuire, 1986; Zaller, 1996). The themes that recur in many reports on wolves may be used as a point from which to commence an analysis of the issues that, on the one hand, refer to aspects of wolves' actual behavior and, on the other hand, indicate how wolf behavior is subjectively perceived by humans. Based upon close examination of the cross-cultural debates about wolves, we cite selective examples of these media reports. In particular, we address three themes that in our view are especially pertinent in the portrayal of wolves. We corroborate these claims and our analysis by academic references that substantiate the importance of these themes. The three themes (which refer to features of actual wolf behavior) are wolf agency, wolf indomitability, and the potential danger that emanates from wolves. We now present these three features in some detail, and subsequently we explain why these themes may arouse notions of evil and the shadow archetype.

\section{Wolf agency}

Agency is a pivotal criterion for judging whether something is animate (Fiske et al., 2007; Gray et al., 2007; Waytz et al., 2010). Wolves display apparent agency in many ways that are being abundantly displayed in the media. Examples of this include the following: Wolves actively search for and use new territory, and their ability to adapt to the human-made landscape reflects their behavioral flexibility. Moreover, wolves' predatory nature and the effectiveness of their hunting further contribute to the impression that they are deliberate, intentional agents. When journalists portray wolves' behavior, they often underscore wolf agency by drawing on agency-rich vocabulary and imagery. For example, exploratory behaviors of wolves near settlements are often portrayed as "lurking" and "roving around" (e.g., Schäfli, 2014a; Winter, 2008).

\section{Wolf indomitability}

"Indomitability" is an expression of an autonomous agent characterized by a reluctance to comply to a rule or command. Wolves, of course, are unaware of human-made rules, but they unknowingly violate a number of implicit expectations that may be present in our thinking about nature and about ourselves. For example, one such belief is that wild animals, including wolves, tend and ought to display a "natural shyness" toward humans. Media coverage of human-wolf encounters often emphasize instances when some wolves allegedly lack shyness and instead inquisitively enter into human settlements (Culiuc, 2015; Sewig, 2016). Consequently, when wolves roam human spaces, they cross a virtual line that divides nature from culture in humans' thinking about the landscape. The implicit ontological divide between wilderness and civilization (Linnell et al., 2015; Plumwood, 2006) is reinforced when wolves are portrayed as perpetrators who "don't belong” within our well-tended human spaces (Fokken, 2015).

When wolves cross the psychological border between nature and culture, they defy human control and qualify as indomitable. At the same time, wolves alter human behavior since sheep-herders, dogowners, and ramblers need to adapt to wolves' presence. Newspaper articles and blog entries frequently cover the rage of people who resist notions that humans should adapt their lives to wildlife, including wolves: An illustration of this is provided by Schäfli (2014a) in a widely read Swiss free sheet, whose article about proposed hardships Swiss sheep herders face because of wolves had the headline "The wolf is victorious-sheep herders give up." 


\section{THE BIG BAD WOLF STEREOTYPE}

\section{Potential danger}

Often, when journalists portray wolves, these animals are presented as having an unruly agency and being potentially dangerous. This is frequently mirrored by presenting humans as passive and by framing humans' orientations toward wolves in terms of "latent insecurity” or "bad gut feelings." For example, Schäfli (2014b, terms in quotation marks indicate first author's translations) stated that it seems that humans inhabiting areas ranged by wolves are fated to wait for "something to happen." Occasionally, authors proffer advice regarding how to behave when facing wolves. However, advising people, for example, "not to run" (Schäfli, 2014b) when encountering a wolf might actually have an effect of promoting fear, since this may evoke connotations of a human being in danger from or hunted by a wolf. Likewise, management plans may inadvertently exacerbate farmers' fear of wolves as farmers must wait for the wolf to kill livestock before they can react by applying for compensation payments (cf. Deter, 2016a; Kowitz, 2012). Thus, notions of potential danger emanating from wolves is a theme that both fuels and pervades media coverage of wolves (Willeke, 2015; Winter, 2008). In these reports, a candid debate about whether wolves really are a threat to human physical or economic integrity is neglected. Instead, news reports dwell upon the possibility of such consequences and thus promote the amorphous fear of wolves. Antiwolf attitudes might therefore be partly fueled by what Drewermann in "Structures of Evil" calls a "reactive hostility in the wake of fear" (first author's translation from Drewermann, 1988, p. 268). The quote from Drewermann may serve as an example of how allegedly factual reports on wolves may reflect or emphasize the Jungian archetype of the shadow.

After having briefly considered three recurring themes in journalists' reporting about wolves, we now consider why the three features of wolves' behavior we presented above may evoke the idea of evil.

\section{Facets of Evil}

What does it mean to consider something as "evil"? In this essay, we have employed the Jungian archetype of the shadow to refer to a category within the human mind in which resides a person's intuitive understanding of what is baleful, diabolical, or malicious. The Jungian conception of the shadow implies that this archetypal category is composed of suppressed and unwanted aspects of one's own psyche. We, however, are not concerned with the genealogy of this archetype. Instead, we are understanding this archetype to be a repository of beliefs and feelings that, inter alia, embody the culturally shared notions of evil. In this section, we draw from an eclectic set of cultural and social scientific sources in order to illuminate the cultural meaning of the term evil. As this essay is reporting on an ongoing exploratory piece of research that is investigating the cultural location of the wolf, we do not engage in a comprehensive exposition of evil. Rather, we identify four interrelated facets of evil and investigate the association of these facets with the characteristics of wolves we discussed in the paragraphs above. Thus, we hope to demonstrate how wolves may have become associated with the idea of evil and how the stereotype of the Big Bad Wolf has been construed and reinforced.

\section{Intentional harm}

The category of behaviors that are thought of as being evil has a strong normative connotation. This normative category is applied to behaviors that may be judged as intentionally adverse to others' wellbeing (Eagleton, 2010). As we have earlier discussed, what appears to be agency pervades wolves' behavior and leads to the attribution of intentionality to wolves. On this understanding, what humans may see as wolves afflicting economic and potentially physical harm on humans may be defined as a facet of evilness. In addition, wolves violate human's categorial assumptions about how wildlife ought to behave: unobtrusively and shyly. In fairy tales and fables, the mythical Big Bad Wolf constitutes evil personified: an active, goaldriven, wicked and immoral agent whose mere existence allegorizes evil in the societies telling these instructive stories.

Rationality is a lauded feature of contemporary European society, and this, coupled with the popularization of comparative psychology and biology, could provide the basis for assessments of wolf behavior that is based upon objective knowledge. However, seemingly irrational sentiments by which wolves are seen as wantonly destructive appear to pervade debates about wolves, suggesting that mythical accounts of wolves may play an important role in human relationships with wolves.

In support of this contention, Immanuel Kant (1756) observed that even when facing intention-free phenomena such as the Lisbon Earthquake of 1755, humans tend to be overpowered by their irrational sentiments, "since fear bereaves them of rational thought" (Kant, 1756, p. 102; first author's translation). Thus, when wolves behave in ways that are unappreciated in human society, these behaviors may inadvertently arouse emotions that associate these behaviors with intentionality and as such with evil. This, we argue, is how the image of the Big Bad Wolf is formed. The Big Bad Wolf stereotype is constructed from the match between wolves' agency and the "intentional harm" facet of the shadow archetype. Such a wantonly destructive wolf is showcased in many cultural renderings 


\section{JÜRGENS AND HACKETT}

of wolves, for example, in Aesop's fables (Aesop, 2008), in Grimm's fairy tales, in Prokofiev's Peter and the Wolf (Malone \& Schulman, 2004), or in Frank Baum's The Wonderful Wizard of Oz: These renderings display wolves as greedy, mischievous villains.

Psychological and cultural scientific research is needed to illuminate the means through which subrational evaluations may work to guide people toward ascribing harmful intentions to wolves, and how influential such ascriptions may be in influencing attitudes and actions. In particular, thorough analysis of media coverage is needed to quantify the degree to which the stereotype of the Big Bad Wolf being wantonly destructive is present in such communications.

\section{Control versus chaos}

An interest in the shadow archetype and its intricateness with human-wolf relations impels a more general consideration of human-nature relations. Fritsche, Jonas, and Fankhänel (2008) proposed that a natural world that is well ordered can be controlled, understood, and managed and meets a fundamental human desire for order. The idea of "Manifest Destiny," according to which civilizing nature is a quasi-sacred duty, is central to humans' striving for controlling nature (Berry, 1999; Miller \& Thompson, 2006; Sezgin, 2012). Kolakowski (1977) and Eagleton (2010) define evil as a force that negates an established order. On this definition, the idea of evil is associated to the attribute of chaos, that is, the absence of order and control.

Terror Management Theory states that humans' need for control and, conversely, human loathing of chaos are fundamental motivations. Scholars like Fritsche et al. (2008), Greenberg et al. (1990), and Rosenblatt et al. (1989) claim that all human striving ultimately is aimed at evading the "terror" of mortality, since dying signifies a maximum of loss of control.

Therefore, there are two dimensions to the indignation evoked in many humans when something defies control: First, the element that defies control resists being classified and mentally or practically managed. It reminds humans of their place within a potentially uncontrollable natural world and the unforeseeable future.

Goethe (1867) merged humans' fear of death with their vain striving for control and from these primordial motives formed Mephistopheles, an incarnation of evil. Mephistopheles introduces himself as the all-negating evil who asserts that everything deserves to perish. Necrophilia, the lust for decay, is another epitome of evilness (Fromm, 1974).

As wolves are animals, they lack a concept of good or bad. However, we may interpret their overt behaviors as corresponding with evilness as an order-defying aspect of nature. To expand upon this, wolves' behaviors display their "animality”; a term Kant (1793, p. 673, first author's translation) employed to substantiate an inclination toward "wild lawlessness." Felthous and Kellert (1987) claim that when compared with peoples' striving for control, the wild lawlessness embodied by wolves verges on evilness. Moreover, wolves evade human control and instead may seem to be living a kind of "satanic freedom"2. For example, when sheepherders in Eastern Germany claim that wolves outwit all measures taken to secure herds (Ulbrich, 2016) and kill livestock in areas "just adjacent to farms" (Deter, 2016c), wolves become the antitheses to humanimposed law, order, and control.

Second, wolves may be seen to defy human control and to therefore be evil, in the sense suggested by Terror Management Theory: Wolves are predators and scavengers and thus signify for humans a kind of memento mori. As predators, wolves have the potential to kill humans. As scavengers, wolves have taken advantage of events such as wars or epidemics to feed on human corpses (Meurer \& Richarz, 2005), and in two recent cases of human deaths, evidence does not exclude the possibility that humans have been victims of foraging wolves (Geist, 2007). Therefore, wolves are not only a paradigmatic case of an insubordinate element of nature; they are easily associated with necrophilia.

It may be plausible that the two-fold association of wolves to chaos and thus to the idea of evil may straightforwardly reinforce the stereotypical image of the Big Bad Wolf. However, empirical evidence is needed to support or refute this association. Specifically, the application of Terror Management Theory to analyze human-wolf relations seems to us a promising endeavor.

\section{Incursions into civilization}

In exploring why wolves may be perceived as indomitable creatures, we assumed that Central Europeans possess an implicit landscape ontology that neatly distinguishes civilization, or culture, from wilderness, or nature. On this assumption, we follow Plumwood (2006) and others, who have proposed that a distinction between wilderness, a realm untouched or at least unmanaged by humans, and civilization, is fundamental to modern Western thought. If Central Europeans believe in this distinction, then this belief is essential for the present discussion as wolves are widely depicted as symbols of wilderness (Kellert, 1985, 2003; Miller \& Thompson, 2006). Aldo Leopold insinuates such a symbol when he famously describes a spark of "green fire" (Leopold, 1949, p. 130) in a dying wolf's eye.

\footnotetext{
${ }^{2}$ Here, we draw upon Anton Szandor La Vey's (1969) concept of satanic freedom as the self-bestowed liberty of doing as one pleases.
} 


\section{THE BIG BAD WOLF STEREOTYPE}

We argue that such symbolic references add to the intricacy of the human-wolf relationship. This is particularly the case within the context of antagonism between nature and culture (Kegel, 2013; Wilson, 1984). Thus, when wild creatures such as wolves enter the human-made environment, they may be perceived to violate the dichotomous ontology of nature and culture, according to which wildlife "belongs in the wilderness" (as an antiwolf protester states in Ulbrich, 2016).

The media frequently report instances where animals enter human spaces, calling these "problem animals": Such reporting may be influenced by the above bifurcated ontology. In a report termed "The Return of the Wilderness," the distinguished German radio transmitter Deutschlandfunk reports that "like no other continent, Europe has been radically conquered by man and subjugated to the rules of civilization" (first author's translation from Seynsche, 2014, p. 2 of the program's manuscript). The feelings and beliefs inherent in such claims reflect the divide in Europeans' thought between nature and culture and the view of humans as being distinct from nature. However, when wild wolves enter the human-controlled environment, they question the veracity of the civilization-wilderness dichotomy. Latour (2012) proposed that aspects of nature and culture are intermingled, and this claim seems to be a more adequate description of reality that is a continuity between civilization and wilderness.

Such a continuity seems to disturb, for example, German farmers, as Culiuc (2015) frames a report on wolves on the online news platform agrarheute.com thus:

The wolf who proved to be devoid of shyness and who struck terror in the hearts of people in the area has been officially identified: It is a male who is the direct descendant from the pack that had recurrently shown behavioral disorders.

Accordingly, the report is headlined "Problem Wolf Stems from Pack with Behavioral Disorders."

By evidencing the fragility of human attempts to tame wild areas, wolves may be seen to possess another equivalence with ideas of evil: They enter the human-controlled landscape as the archetype of the shadow may come threaten a peaceful state of mind. However, empirical research is needed to investigate the relationship between a worldview that emphasizes nature and civilization as distinct from each other and negative attitudes toward invasive wolves.

\section{Challenging human sovereignty}

Rousseau (1756) and Voltaire (1756) sought to define humankind's place within-or opposing-nature. The idea that a human being is embedded within the natural world and must therefore yield to natural powers stronger than himself or herself matched Rousseau's ideal of man. Voltaire's stance, conversely, was one of lamenting that man may be "derided by incontrollable natural powers, ... thus we are just the small cogs that make run the machine. In God's view, we are no more valuable than the beasts that devour us" (Voltaire, 1756, p. 56, first author's translation). A 2010 article in the German conservative newspaper Die Welt reflected these two positions in its reporting of two mayors of Bavarian municipalities into which a wolf has returned, citing them as follows: "man must have priority over an animal!" and "It is our conviction that the wolf doesn't have a right to live with us. This is a cultural landscape and not a wildlife reserve.... We won't accept that an animal harasses us!" (first author's translation).

The statements above reflect similar sentiments to many articles that have been published about wolves. These statements appear to express negativity toward the wolf and its protectors based on wolf opponents' alleged belief that the wolf is incumbent of a lower position to humans on evolutionary, intellectual, and moral scales. Boccato and colleagues (2008) have emphasized how deeply the human-animal divide is ingrained within the human psyche. Wild and uncultivated animals are portrayed as categorially different from, and less valuable than, sophisticated and civilized humans (Demoulin et al., 2004; Leyens et al., 2000). Dinzelbacher (2012) claims that the idea of a natural hierarchy headed by humans is notably inspired by Christian belief: This belief, Dinzelbacher says, comes with the implicit expectation, and the practically enforced consequence, that other life-forms must yield to human sovereignty.

By their presence within cultural environments, wolves violate their ascription to the realm of inferior animals that are under human control. Wolves do not readily yield to human will and thus challenge the relative ontological positions to which Western humans have allocated themselves and wolves. On this understanding, the frequently cited lack of shyness seen in some Central European wolves may be perceived as wolves' displaying a lack of respect to humansas challenging human sovereignty. This may be reflected in the naming of a terrorist who pursues an individualistic agenda "outside of a formal organisational or command structure" as a "lone-wolf terrorist" (Phillips, 2011, p. 1).

Furthermore, purposefulness is sometimes attributed to wolf behavior. For example, Schäfli's (2014a) headline "The wolf is victorious-sheep herders give up" refers to how the presence of wolves has required livestock herders to change the herding practices developed over centuries in wolf-free habitats. However, he tacitly 


\section{JÜRGENS AND HACKETT}

addresses the stereotype of the Big Bad Wolf when he claims that "the wolf" has the intention to (re-)gain the reign of the cultural landscape.

Also, not only do wolves rival human hunters as the top predators in Central European forests; in theory, they could make humans their prey, and some claim that historically they have done this (Geist, 2007; Willeke, 2015). In these various ways, the actual wolves who have returned to roam Central European landscapes unsuspectingly give rise to the image of a powerful baleful creature, the Big Bad Wolf, effectively questioning our human understanding of ourselves as sovereigns in this world. An introduction to another of Schäfli's reports on wolves in Vättis, Switzerland, seems designed to activate the image of the Big Bad Wolf from ancient fairy tales in contemporary humans' unconscious: “at night time, wolves sneak through the village. A woman happened to look an alpha male right into its gleaming eyes" (Schäfli, 2014b, first author's translation).

Theoretical assessments of human-predator relations seem to support our claim that peoples' attitudes toward wildlife are intricate with their overall systems of beliefs relative to their place in nature (cf. Hackett, 1995; Linnell et al., 2015). Support comes, for example, from Bjerke and Kaltenborn (1999), who have reported results from questionnaire studies on people's attitudes toward carnivores. Their results show that respondents who were sympathetic to the idea of human-predator coexistence tend toward an ecocentric worldview, while respondents who were skeptical of such a coexistence tended toward an anthropocentric worldview. However, our aim has been to demonstrate the existence of a deeply rooted dynamic present in human-wolf relations that needs in-depth investigation beyond the employment of standardized questionnaires. Thorough empirical investigation employing a variety of qualitative and quantitative methods is needed to corroborate the veracity of the claim that peoples' attitudes toward wolves are interconnected with their attitudes to wildlife and to nature more generally, and specifically that these attitudinal networks embody myths and cultural stereotypes.

\section{Conclusion}

In this essay, we have argued that in the thoughts, feelings, and imaginations of contemporary Central Europeans, the stereotype of a Big Bad Wolf, a sinister-looking creature with wicked intent, is psychologically real and informs beliefs and sentiments toward wolves. Anecdotally, we note that when we explain our research to lay persons, they often concede that such a stereotype exists, and they refer to the wolf figure in fables and fairy tales, offering explanations such as, "Indeed, wolves are seen as wicked by many, and I believe this is due to the Big Bad Wolf being the antihero in tales like Little Red Riding Hood or The Three Little Pigs!” In accord with this intuition, the account presented in this essay suggests that such cultural renderings of wolves reinforce the association of actual wolves with the shadow archetype. Notwithstanding this, our research is moreover directed at more far-reaching questions such as the ones we put forth in the introduction: How did wolves become allegories of evilness in the first place? Why is the idea of evil one of the pervasive leitmotifs associated with these animals?

In our attempt to adumbrate an answer to this complex set of questions, we have argued that wolves evoke the idea of evil by virtue of how people perceive aspects of their behavior. We have further proffered an apparent correspondence between wolf behavior and the Jungian shadow archetype, which emphasizes the character traits of a Big Bad Wolf stereotype. Such a wolf is seen as a baleful creature with intentions to economically and physically harm people, to defy human control and to perturbate the human-conceived order of nature. We have drawn from a variety of cultural sources and have exemplified how this stereotype is embodied within contemporary journalistic coverage of wolves that supports our claim that wolves are seen to embody a specifically defined sense of evil. If wolves are implicitly associated with evilness, then the wolves encountered in reality are tainted by the Big Bad Wolf stereotype as it has been painted in fairy tales. It is therefore not surprising that the emotions displayed in debates about wolves may be strong and often resistant to fact.

The mythical Big Bad Wolf stereotype, we suggest, is one influential factor guiding peoples' attitudes toward wolves. However, it is obvious that other factors need to be taken into account that impact on human-wolf relations. Not all people in Central Europe or elsewhere in the Western world denounce wolves, and those who do refer to various reasons, many of which relate to the possible socioeconomic impacts of wolves' predatory behavior. Our exploratory analysis is therefore open to include additional factors that might contribute to explaining why attitudes toward wolves are not entirely grounded in objective biological and behavioral facts. Our proposal is that wolf opponents' attitudes seem to exhibit an inherent logic that is structured according to an emotional rationale by which aspects of wolf behavior are felt to systematically correspond with facets of the idea of evil, akin to the Jungian shadow archetype-thus creating the stereotype of the Big Bad Wolf. However, possible additional factors are required to explain how the same aspects of wolf behavior motivate wolf enthusiasts to view wolves as noble savages. 


\section{THE BIG BAD WOLF STEREOTYPE}

Beyond wolves, our exploration is an example of how human relationships to potentially "problematic" wildlife species can be analyzed in terms of deeper-seated psychological constructs. Investigations of these dynamics underlying the cultural positioning of such "problematic" species may best be undertaken within a broad ecopsychological perspective employing hermeneutical analysis together with systematic empirical qualitative and quantitative methods. We have suggested research questions that our exploratory investigation specifically inspires. Moreover, the stability or variability of the Big Bad Wolf stereotype across cultures' histories and across different cultures remains to be explored. Positive attitudes toward wolves and their association with the stereotype of "wolf the noble savage" also warrant inquiry, as do the interindividual and intercultural similarities and differences that are related to both positive and negative stereotypes. By conducting transdisciplinary research into the role of individual and cultural stereotypes and associations, it may be hoped that a greater understanding will be developed of peoples' relations with wolves and enhance wildlife management efforts.

\section{Acknowledgments}

The first author is indebted to Dr. Eva Edelmann-Ohler for referring her to the cultural renderings of evil and for her encouragement to publish the work. Notably, she should like to express her gratitude to the Deutsche Wildtier Stiftung for funding her work on humanwildlife relations through their research award.

\section{Author Disclosure Statement}

No competing financial interests exist for either of the authors.

\section{REFERENCES}

Aesop. (2008). Aesop's fables. A new translation by Laura Gibbs (L. Gibbs, Trans.). Oxford, UK: Oxford University Press.

Andersen, R., Linnell, J. D. C., Hustad, H., \&t Brainerd, S. M. (2003). Large predators and human communities in Norway (Vol. 25). Trondheim: Norwegian Institute for Nature Research.

Ansorge, H., Holzapfel, M., Kluth, G., Reinhardt, I., \&t Wagner, C. (2010). Die Rückkehr der Wölfe. Das erste Jahrzehnt. Biologie in unserer Zeit, 40, 244-253.

Bath, A., \&t Majić, A. (2001). Human dimensions in wolf management in Croatia. Manuskript i nettversjon. Large Carnivore Initiative for Europe.

Berry, T. (1999). The Great Work: Our way into the future. New York: Bell Tower.

Bisi, J., Liukkonen, T., Mykrä, S., Pohja-Mykrä, M., \&t Kurki, S. (2010). The good bad wolf-wolf evaluation reveals the roots of the Finnish wolf conflict. European Journal of Wildlife Research, 56, 771-779.
Bjerke, T., \& Kaltenborn, B. P. (1999). The relationship of ecocentric and anthropocentric motives to attitudes toward large carnivores. Journal of Environmental Psychology, 19, 415-421.

Boccato, G., Capozza, D., Falvo, R., \& Durante, F. (2008). The missing link: Ingroup, outgroup and the human species. Social Cognition, 26, 224-234.

Caluori, U., \& Hunziker, M. (2001). Der Wolf: Bedrohung und LichtgestaltDeutungsmuster in der Schweizer Bevölkerung. Forest, Snow, and Landscape Research, 76, 169-190.

Culiuc, N. (2015, March 31). Problem-Wolf stammt aus verhaltensauffälligem Rudel. agrarheute.com. Retrieved from www.agrarheute.com/problem-wolf-stammtaus-verhaltensauffaelligem-rudel

Davies, A. (2015, October 14). Understanding fairy tales: A look into the Big Bad Wolf archetype. Watkins. Retrieved from http://www.watkinspublishing.com/ understanding-fairy-tales-a-look-into-the-big-bad-wolf-archetype

Demoulin, S., Leyens, J. P., Paladino, M. P., Rodriguez-Torres, R., Rodriguez-Perez, A., \& Dovidio, J. (2004). Dimensions of "uniquely" and "non-uniquely" human emotions. Cognition and Emotion, 18, 71-96.

Deter, A. (2016a, March 31). Weidetierhalter füchten den Wolf. topagrar online. Retrieved from http://www.topagrar.com/news/Home-top-News-Weidetierhalterfuerchten-den-Wolf-2920361.html

Deter, A. (20166, November 16). Weidetierhaltung geht nur ohne Wolf. topagrar online. Retrieved from http://www.topagrar.com/news/Home-top-News-AbLWeidetierhaltung-geht-nur-ohne-Woelfe-5645753.html

Deter, A. (2016c, November 23). Wölfe reißen Schafe direkt neben Hof. topagrar online. Retrieved from http://www.topagrar.com/news/Home-top-News-Woelfe-reissenSchafe-direkt-neben-Hof-5864681.html

Die Welt. (2010, October 24). Problemwolf verbreitet Angst in Oberbayern. Die Welt. Retrieved from http://www.welt.de/vermischtes/article10505186/Problemwolfverbreitet-Angst-in-Oberbayern.html

Dinzelbacher, P. (2012). Gebrauchstiere und Tierphantasien. Mensch und Tier in der europäischen Geschichte. Aus Politik und Zeitgeschichte, 62, Jahrgang 8-9(20. Februar 2012), 27-34.

Drewermann, E. (1988). Strukturen des Bösen. Paderborn: Ferdinand Schöningh. Eagleton, T. (2010). On evil. New Haven: Yale University Press.

Egger, B. (2001). Raubtiere, mythologisch und tiefenpsychologisch betrachtet. Hunziker, M. \& Landolt, R. $(\mathrm{Hg})$ : Humans and predators in Europe: Research on how society is coping with the return of wild predators. Forest, Snow, and Landscape Research, 76, 53-90.

Felthous, A. R., \& Kellert, S. R. (1987). Psychosocial aspects of selecting animal species for physical abuse. Journal of Forensic Sciences, 32, 17131723.

Fiske, S. T., Cuddy, A. J., \& Glick, P. (2007). Universal dimensions of social cognition: Warmth and competence. Trends in Cognitive Sciences, 11, 77-83.

Flykt, A., Johansson, M., Karlsson, J., Lindeberg, S., \& Lipp, O. V. (2013). Fear of wolves and bears: physiological responses and negative associations in a Swedish sample. Human Dimensions of Wildlife, 18, 416-434.

Fokken, U. (2015, May 7). Das Märchen vom Bösen Wolf. TAZ.de. Retrieved from http://www.taz.de/!5009533

Fritsche, I., Jonas, E., \& Fankhänel, T. (2008). The role of control motivation in mortality salience effects on ingroup support and defense. Journal of Personality and Social Psychology, 95, 524-541.

Fromm, E. (1974). Anatomie der menschlichen Destruktivität. Stuttgart, Germany: Deutsche Verlags-Anstalt. 


\section{JÜRGENS AND HACKETT}

Gärtner, S., \&t Hauptmann, M. (2005). Das sächsische Wolfsvorkommen im Spiegel der Jägerschaft vor Ort-Ergebnisse einer anonymen Umfrage. Beiträge zur Jagd- und Wildforschung, 30, 223-230.

Gawronski, B., \& Payne, B. K. (2011). Handbook of implicit social cognition: Measurement, theory, and applications. New York: Guilford Press.

Geist, V. (2007). When do wolves become dangerous to humans? Calgary, Canada: University of Calgary. Retrieved from https://web.archive.org/web/ 20080910164737/http://wolfcrossing.org/blog/wp-content/uploads/2007/10/ carnegie-no1.pdf

Goethe, J. W. (1867). Faust: Eine Tragödie. Leipzig: Philipp Reclam Jun.

Gray, H. M., Gray, K., \& Wegner, D. M. (2007). Dimensions of mind perception. Science, 315, 619 .

Greenberg, J., Pyszczynski, T., Solomon, S., Rosenblatt, A., Veeder, M., Kirkland, S., \& Lyon, D. (1990). Evidence for terror management theory II: The effects of mortality salience on reactions to those who threaten or bolster the cultural worldview. Journal of Personality and Social Psychology, 58, 308-318.

Hackett, P. M. W. (1995). Conservation and the consumer: Understanding environmental concern. New York: Routledge.

Hasselmann, S. (2015, July 2). Von blauäugig bis hysterisch. Deutschlandfunk.

Hunziker, M., Egli, E., \& Wallner, A. (1998). Return of predators: Reasons for existence or lack of public acceptance. KORA Ber, 3, 25-30.

Jacobs, M. H., Vaske, J. J., Dubois, S., \& Fehres, P. (2014). More than fear: Role of emotions in acceptability of lethal control of wolves. European Journal of Wildlife Research, 60, 589-598.

Jung, C. G. (1990). Archetypen. München: DTV.

Kaczensky, P. (2006). Medienpräsenz-und Akzeptanzstudie 'Wölfe in Deutschland'. Freiburg im Breisgau, Germany: University of Freiburg.

Kaltenborn, B., Bjerke, T., \& Strumse, E. (1998). Diverging attitudes towards predators: Do environmental beliefs play a part? Human Ecology Review, 5, $1-9$.

Kaltenborn, B. P., \&t Bjerke, T. (2002). The relationship of general life values to attitudes toward large carnivores. Human Ecology Review, 9, 55-61.

Kant, I. (1756). Von den Ursachen der Erderschütterungen bei Gelegenheit des Unglücks, welches die westlichen Länder von Europa gegen das Ende des vorigen Jahres getroffen hat. In W. Breidert (Ed.), Die Erschütterung der vollkommenen Welt (pp. 100-107). Darmstadt: Wissenschaftliche Buchgesellschaft.

Kant, I. (1793). Die Religion innerhalb der Grenzen der bloßen Vernunft. Königsberg: Friedrich Nicolovius.

Kegel, B. (2013). Tiere in der Stadt: Eine Naturgeschichte. Köln, Germany: DuMont Buchverag.

Kellert, S. R. (1985). Public perceptions of predators, particularly the wolf and coyote. Biological Conservation, 31, 167-189.

Kellert, S. R. (2003). Kinship to mastery: Biophilia in human evolution and development. Washington, DC: Island Press.

Kolakowski, L. (1977). Des Teufels Pressekonferenz. In L. Reinisch (Ed.), Leben trotz Geschichte (pp. 202-217). München, Germany: R. Piper \& Co.

Kowitz, D. (2012, April 26). Des Menschen Wolf. Die Zeit, Dossier, 18, 15-17.

La Vey, A. S. (1969). The satanic bible. New York: Avon Books.

Latour, B. (2012). Das Parlament der Dinge (2nd ed.). Frankfurt am Main, Germany: Suhrkamp.

Leopold, A. (1949). Sand County almanac: And sketches here and there. New York: Oxford University Press.
Leyens, J.-P., Paladino, P. M., Rodriguez-Torres, R., Vaes, J., Demoulin, S., RodriguezPerez, A., \&t Gaunt, R. (2000). The emotional side of prejudice: The attribution of secondary emotions to ingroups and outgroups. Personality and Social Psychology Review, 4, 186-197.

Linnell, J. D., Kaczensky, P., Wotschikowsky, U., Lescureux, N., \& Boitani, L. (2015). Framing the relationship between people and nature in the context of European conservation. Conservation Biology, 29, 978-985

Macrae, C. N., \&t Bodenhausen, G. V. (2000). Social cognition: Thinking categorically about others. Annual Review of Psychology, 51, 93-120.

Majić, A., \&t Bath, A. J. (2010). Changes in attitudes toward wolves in Croatia. Biological Conservation, 143, 255-260.

Malone, P., \& Schulman, J. (2004). Sergei Prokofiev's Peter and the Wolf. New York: Alfred A. Knopf.

McGuire, W. J. (1986). The myth of massive media impact: Savagings and salvagings. In G. Comstock (Ed.), Public communication and behavior (Vol. 1, pp. 173-257). Orlando, FL: Academic Press.

Meier, B. P., Robinson, M. D., \&t Clore, G. L. (2004). Why good guys wear whiteautomatic inferences about stimulus valence based on brightness Psychological Science, 15, 82-87.

Meurer, H., \&t Richarz, K. (2005). Von Werwölfen und Vampiren. Stuttgart, Germany: Kosmos.

Miller, J., \& Thompson, J. (2006). National Geographic Almanac of American History. Washington DC: National Geographic Society.

Phillips, P. J. (2011). Lone wolf terrorism. Peace Economics, Peace Science and Public Policy, 17, doi:10.2202/1554-8597.1207.

Plumwood, V. (2006). The concept of a cultural landscape: Nature, culture and agency of the land. Ethics \& the Environment, 11, 115-150.

Rosenblatt, A., Greenberg, J., Solomon, S., Pyszczynski, T., \&t Lyon, D. (1989). Evidence for terror management theory: I. The effects of mortality salience on reactions to those who violate or uphold cultural values. Journal of Personality and Social Psychology, 57, 681-690.

Rousseau, J.-J. (1756). Brief über die Vorsehung. In W. Breidert (Ed.), Die Erschütterung der vollkommenen Welt (pp. 79-96). Darmstadt: Wissenschaftliche Buchgesellschaft.

Schäfli, R. (2014a, July 29). Der Wolf gewinnt-die Schafzüchter geben auf. 20 Minuten.

Schäfli, R. (2014b, September 1). Um Mitternacht starrte der Wolf sie an. 20 Minuten.

Sewig, C. (2016, May 10). Das Rätsel um den toten Wolf Kurti. Die Welt. Retrieved from http://www.welt.de/regionales/hamburg/article155235154/Das-Raetselum-den-toten-Wolf-Kurti.html

Seynsche, M. (2014). Die Rückkehr der Wildnis: Wie Europa seine ökologische Vielfalt wiederentdeckt [Deutschlandfunk], Gesichter Europas.

Sezgin, H. (2012). Dürfen wir Tiere für unsere Zwecke nutzen? Aus Politik und Zeitgeschichte 62. Jahrgang, 8-9(20. Februar 2012), 3-8.

Skogen, K. (2001). Who's afraid of the Big, Bad Wolf? Young people's responses to the conflicts over large carnivores in Eastern Norway. Rural Sociology, 66, 203-226.

Skogen, K., \& Thrane, C. (2007). Wolves in context: Using survey data to situate attitudes within a wider cultural framework. Society \& Natural Resources, 21, 17-33.

Ulbrich, J. (2016, November 22). Dürfen Wölfe geschossen werden? Sächsische Zeitung. Retrieved from http://www.sz-online.de/nachrichten/ 
THE BIG BAD WOLF STEREOTYPE

bilder-von-der-demonstration-gegen-woelfe-g18185.html?Storyld= 3546156

Voltaire. (1756). Gedicht über die Katastrophe von Lissabon. In W. Breidert (Ed.), Die Erschütterung der vollkommenen Welt (pp. 58-76). Darmstadt: Wissenschaftliche Buchgesellschaft.

Waytz, A., Gray, K., Epley, N., \& Wegner, D. M. (2010). Causes and consequences of mind perception. Trends in Cognitive Sciences, 14, 383-388.

Wild-Eck, S., \& Zimmermann, W. (2001). Raubtierakzeptanz in der Schweiz: Erkenntnisse aus einer Meinungsumfrage zu Wald und Natur. Forest, Snow, and Landscape Research, 76, 285-300.

Willeke, S. (2015). Die Wölfe kommen. Die Zeit, Dossier, (14), 11-13.

Williams, C. K., Ericsson, G., \& Heberlein, T. A. (2002). A quantitative summary of attitudes toward wolves and their reintroduction. Wildlife Society Bulletin, 30, 575-584.

Wilson, E. O. (1984). Biophilia. New York: Harvard University Press.

Winter, S. (2008). Das Rotkäppchen-Syndrom. Der Spiegel, 43.

Wotschikowsky, U. (2006). Wölfe, Jagd und Wald in der Oberlausitz. Report, VAUNA. Oberammergau, Germany.
Zaller, J. (1996). The myth of massive media impact revived: New support for a discredited idea. In D. C. Mutz, P. M. Sniderman, \&t R. A. Brody (Eds.), Political persuasion and attitude change (pp. 17-78). Ann Arbor, MI: University of Michigan Press.

Address correspondence to: Uta Maria Jürgens Social Sciences in Landscape Research Group Research Unit Economics and Social Sciences Swiss Federal Research Institute WSL Zürcherstraße 111 CH-8903 Birmensdorf, Switzerland E-mail: Juergens@wsl.ch

Received: September 30, 2016 Accepted: January 2, 2017 